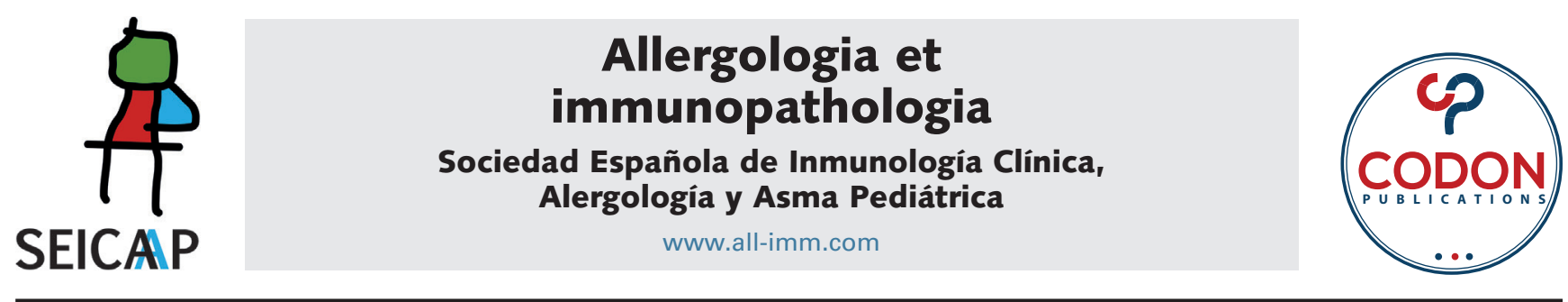

ORIGINAL ARTICLES

\title{
Antibodies to Der p 1 and Der p 2 in allergic patients
}

\section{Renata Harumi Cruz a*, Leandro Hideki Ynouea, Carolina Sanchez Arandab, Dirceu Soléb, Antonio Condino-Neto ${ }^{\mathrm{a}}$}

a Laboratory of Human Immunology, Department of Immunology, Institute of Biomedical Sciences IV, Universidade de São Paulo, São Paulo, Brazil

${ }^{b}$ Department of Pediatrics, Division of Allergy, Clinical Immunology and Rheumatology, Universidade Federal de São Paulo, São Paulo, Brazil

Received 27 June 2020; Accepted 26 October 2020

Available online 1 March 2021

\author{
KEYWORDS \\ allergen; \\ allergy; \\ Dermatophagoides \\ pteronyssinus; \\ antibodies
}

\begin{abstract}
Introduction and objectives: Atopic individuals are characterized by increased lgE production and Th2 response if exposed to certain antigens. It is known that the mother transfers antimite antibodies to the fetus and newborn, IgG thru the placenta, and IgA thru breastfeeding, but it is not clear whether there is a protective mechanism mediated by them concerning the development of future allergies. This study aimed to compare the levels of IgA, IgG, and IgE antibodies specific to Der p 1 and Der p 2 between atopic and healthy individuals.

Methods: Serum samples of 98 patients and 44 healthy controls were subjected to quantification for specific IgE, IgG, and IgA antibodies against Der $\mathrm{p} 1$ and Der $\mathrm{p} 2$ by ImmunoCap $^{\circledR}$ and ELISA, and subjected to statistical analysis as indicated.

Results: Atopic patients had higher serum levels of IgE, IgG, and IgA specific to Der $\mathrm{p} 1$ and Der p 2. The correlation was more robust between IgE and IgG antibodies.

Conclusions: Allergic patients produce higher levels of antibodies against Der $\mathrm{p} 1$ and Der $\mathrm{p}$ 2 compared with healthy individuals. The mechanisms involved still require detailed studies.

(c) 2021 Codon Publications. Published by Codon Publications.
\end{abstract}

*Corresponding author: Renata Harumi Cruz, Laboratory of Human Immunology, Department of Immunology, Institute of Biomedical Sciences IV, Universidade de São Paulo, São Paulo, Brazil. Email address: r.haru02@gmail.com 


\section{Introduction}

Epidemiological studies report an increase in the prevalence of allergic diseases worldwide, especially in developing countries.1-3 These diseases, for the most part, are mediated by class E (IgE) antibodies specific to substances that nonallergic individuals do not normally produce and are characterized by the activation of type I allergic inflammatory reaction of Gell and Coombs. ${ }^{4,5}$

Household dust mites are considered the main etiological cause of respiratory allergies in our environment. ${ }^{6}$ In spite of geographic differences, over $85 \%$ of asthma patients are located in regions of North America and South America, followed by Europe and Southeast Asia and Australia, ${ }^{7}$ and about $90 \%$ of these patients may become sensitized to different allergens.

One of the main genera of household dust mites is Dermatophagoides sp. found in several places, preferably in tropical regions such as Brazil, Southern United States, Puerto Rico, and Venezuela. ${ }^{8}$ In the city of São Paulo, for example, it was observed that the species Dermatophagoides pteronissynus and Blomia tropicalis represent $50 \%$ and $26 \%$ of the allergens present in the dust of home interiors, respectively. ${ }^{9}$ A study carried out in the city of Salvador, in the Brazilian state of Bahia, demonstrated that these species are also the main inducers of allergic sensitization and responsible for the highest frequency percentages of positive skin tests. ${ }^{9}$ A recent national study has found that $63.9 \%$ of allergic patients are sensitized to $D$. pteronissynus. ${ }^{6}$

With improvements in molecular biology, it has been possible to characterize the allergenic components of $D$. pteronissynus, among them those of Group 1 (Der p 1) and Group 2 (Der p 2). Der p 1 is the most abundant allergen found in mite feces and the main inducer of the IgEmediated response in patients allergic to household dust, ${ }^{10}$ but Der p 2 is also an important allergy inducer. ${ }^{11}$

In 1911, Leonard Noon was the first to demonstrate that subcutaneous inoculation of pollen extracts acted by suppressing immediate conjunctival sensitivity to pollen, and with this idea, allergen-specific immunotherapy for allergic diseases mediated by lgE was created. ${ }^{12}$ Immunotherapy is a treatment which consists of inducing immune tolerance by administering the allergen (pollen, dust mites, pet hair, etc.). ${ }^{13}$ This treatment seeks to reduce symptoms in allergic patients related to rhinitis, conjunctivitis, and allergic asthma. ${ }^{13}$

One explanation for the success of immunotherapy is to change the profile of antibodies developed against the allergen, leading to an increase in allergen-specific IgG, a decrease in specific lgE, in addition to IgA synthesis. ${ }^{14}$ Some studies have reported modulation of the antibody profile between IgG and IgE, where IgG4 would act by blocking the interaction between lgE and allergen, consequently leading to an IgE neutralization mechanism. ${ }^{15}$ There are also longterm immunotherapy studies that demonstrate change in lymphocyte profile, from Th2 to Th1, as well as an increase in the number and functions of regulatory T lymphocytes. ${ }^{16}$

Considering the relevance of antibodies in the pathophysiology of allergic diseases, as well as their role in the mechanisms of specific allergen immunotherapy, in this study, we compared the concentration of serum IgE, $\lg G$, and IgA antibodies specific for Der $p 1$ and Der $p 2$ of allergic patients with healthy individuals without a history of allergy.

\section{Materials and methods}

This was a cross-sectional study with convenience sample. The sample size was calculated from the prevalence of allergic sensitization among patients with allergy and healthy individuals, ${ }^{6}$ with a significance of $5 \%$ associated with a 95\% confidence level. The software used was PASS (Power Analysis and Sample Size) ${ }^{13}$-NCSS. Thus, the sample should account for 80 patients and 40 healthy individuals.

Patients with a medical diagnosis of allergic disease (asthma, allergic rhinitis, allergic conjunctivitis, atopic dermatitis, food allergy, and wheezing infants) aged between six months and 40 years were invited to participate in the study. These patients were followed up at the Allergy Clinic of the Allergy Discipline, Clinical Immunology and Rheumatology-UNIFESP-EPM, and had a positive immediate hypersensitivity skin test (IHST) to home dust mites. The diagnosis of allergic diseases was made based on international recommendations. The IHST was characterized as positive when an induration papule with an average diameter $\geq 3 \mathrm{~mm}$ appeared on the skin puncture through a drop of allergen $D$. pteronissynus (IPI-ASAC ${ }^{\circledR}$ ) arranged on the surface of the forearm and compared with a positive control (histamine) and negative excipient. ${ }^{17}$ Patients on systemic immunosuppressive therapy or allergen-specific immunotherapy were not considered eligible for this research. ${ }^{18}$

The control group comprised individuals with no medical history of allergic disease, recruited from childcare outpatient clinics, and during the collection of general examination at São Paulo Hospital and Federal University of São Paulo, São Paulo (USP and UNIFESP). Every control group participant had a negative specific IHST.

Thus, the participants were divided into two groups: allergic with clinical history of allergies, positive IHST, and serum IgE specific to $D$. pteronissynus present, and the control group without a clinical history of allergies and negative IHST. All the participants in both groups signed the Free and Informed Consent Term (FICF) after being informed about the objectives of the study. The study, the experimental protocol, and the consent form conformed to the ethical requirements and were analyzed and approved by the Ethics Committee on Research with Human Beings of ICB-USP, approval number 49353615.8.0000.5467.

All participants underwent peripheral blood collection in a dry tube to obtain serum. After clot retraction, it was centrifuged, and the serum obtained was separated into aliquots to quantify total and specific serum IgE for D. pteronissynus and its allergens Der $\mathrm{p} 1$ and Der $\mathrm{p} 2$, as well as IgA and IgG specific to the same allergens, and subsequent purification. The quantification of total and specific IgE for the $D$. pteronissynus extract (source of the $D$. pteronissynus) was performed using the ImmunoCAP ${ }^{\circledR}$ technique (Thermofisher, Uppsala, Sweden). Anti-human total IgE quantification was already coupled to the ImmunoCAP ${ }^{\circledR}$ cellulose solid phase.

An ELISA assay was performed to determine the levels of IgE, IgA, and IgG specific to Der p 1 and Der $\mathrm{p} 2$. Briefly, polystyrene plates (96-well high-biding plates; BD 
Biosciences) were sensitized with $1 \mu \mathrm{g} / \mathrm{mL}$ of Der $\mathrm{p} 1$ or Der $\mathrm{p} 2$ diluted in carbonate buffer. After incubation for $15-18 \mathrm{~h}$ at $4^{\circ} \mathrm{C}$, the plates were washed for four times with phosphate buffer solution (PBS) plus Tween ${ }^{\circledR} 20$ (PBS-T 0.1\%; Promega, Madison, WI, USA). The plates were blocked for one hour at room temperature with PBS-T plus $1 \%$ bovine serum albumin (PBS-T-BSA 1\%). After blocking, the plates were washed again, followed by the addition of serum samples (IgE/Der p 1 - 1: 6; IgE/Der p 2 - 1:16; IgA/Der p 1 1:60; IgA/Der p 2 - 1:80; IgG/Der p 1 - 1:150; and IgG/Der p 2 - 1:300) and incubated for another two hours at room temperature. After rewashing, biotinylated secondary antiIgE antibody (1:1000), anti-human IgG, and anti-human IgA conjugated to peroxidase were added and incubated for one hour at room temperature.

The IgE plates were washed again and incubated with an Avidin-peroxidase solution (1:1000 Avidin peroxidase; eBioscience) for 30 min at room temperature. After another washing cycle, the plates were added $50 \mu \mathrm{L}$ of tetramethylbenzidine reagent $\left(\mathrm{TMB}^{\circledR}\right.$; BD Biosciences). After $20 \mathrm{~min}$, the reaction was stopped with $50-\mu \mathrm{L}$ sulfuric acid (30\%) and the absorbance was read at a wavelength of $450 \mathrm{~nm}$ using a microplate reader (Molecular Devices, Sunnyvale, CA, USA).

Concentration of the samples was estimated as arbitrary units per milliliter $(\mathrm{AU} / \mathrm{mL})$ by comparing with a standard curve using a serum with high levels of IgA or IgG specific to Der p 1 or Der p 2. For the evaluation of antibody levels, the cut-off was performed (mean + two times the standard deviation [mean $+2 \times \mathrm{SD}$ ]) to determine the cut-off level of specific IgE, IgG, and IgA antibodies to Der p 1 and Der $\mathrm{p} 2$.

After the D'Agostino-Pearson test, we used Student's $t$-test and Bartlett's test to verify the existence or not of homogeneity between the variances, followed by the analysis of variance (ANOVA). Evaluation of the correlation between the levels of antibodies was done by the Spearman's method. All analyses were performed using Prism 4.00 Software (Graph Pad Softawer Inc.).

\section{Results}

This analytical and observational study made it possible to evaluate the quantification of antibodies from the results obtained. Of the 142 participating individuals, 98 formed the allergic group and 44 were in the control group. In the allergic group, there was a higher proportion of patients with asthma and allergic rhinitis, followed by allergic conjunctivitis; atopic dermatitis; food allergy, and wheezing infants. All members of the control group had a negative result for the determination of specific antibodies to Der p 1 and Der p 2 (Table 1).

The mean age of the groups was 21.3 , while the median was 24 . There was a statistically significant difference in age between the groups analyzed. Determination of serum levels of specific antibodies to Der $p 1$ and Der $p 2$ was performed by ELISA. To assess the levels (anti-Der $\mathrm{p} 1$ and anti-Der $p$ 2) observed, and to compare them between the two groups, we adopted as a cut-off criterion the mean value of specific antibody for each of the subtypes (IgE, $\operatorname{lgG}$, and $\lg A$ ), plus two standard deviations (Figures 1-3). Values above this cut-off point were considered high. Thus, the results showed that allergic patients had higher levels of specific antibodies to Der p 1 and Der p 2 compared with controls for all evaluated antibodies.

Then we performed the correlation test between specific IgE, IgG, and IgA antibodies to Der $\mathrm{p} 1$ and Der $\mathrm{p} 2$ of the allergic group (Figures $4 \mathrm{~A}-\mathrm{C}$ and $5 \mathrm{~A}-\mathrm{C}$ ). Despite the difference found between specific IgE and IgG levels for both Der $\mathrm{p} 1$ and Der p 2, there was a correlation between the levels of specific IgE and those of IgG and IgA specific to both allergens. The strength of the correlation was greater between IgE and IgG ( $r=0.7153$ for Der $p 1$ and 0.6954 for Der $p$ 2) than between IgE and IgA $(r=0.3792$ for Der $p 1$ and 0.4884 for Der $\mathrm{p} \mathrm{2}$ ).

\section{Discussion}

The progression of atopy is a sequence of development of allergic diseases. Most of the time it starts in childhood with eczema and progresses to asthma and rhinitis, and this progression of allergic reaction is known as "atopic march." 19 More than $90 \%$ of asthma cases in children are associated with a state of atopy. ${ }^{20}$ This increase may be due to better recognition of the disease, an increase in genetically predisposed individuals, and environmental factors such as pollution, diet, or exposure to allergens. ${ }^{21}$ The present study evaluated the associations and comparisons of specific IgA and IgG antibodies and sought to understand the possible relationship between specific IgA and IgG antibodies in allergic reactions.

Table 1 Demographic data on the individuals that participated in the study.

\begin{tabular}{|c|c|c|c|}
\hline \multirow[b]{2}{*}{ Gender } & & Allergic & Healthy contro \\
\hline & & $51 \mathrm{~F}$ & $27 \mathrm{~F}$ \\
\hline Age (Years old)* & & $26,2 \pm 11,7$ & $21,2 \pm 9,3$ \\
\hline \multirow[t]{5}{*}{ Clinical diagnostic } & Asthma & $43 \%$ & $0 \%$ \\
\hline & Atopic dermatitis (AD) & $14 \%$ & $0 \%$ \\
\hline & Food allergy (FA) & $8 \%$ & $0 \%$ \\
\hline & Wheezing infant & $3 \%$ & $0 \%$ \\
\hline & Allergic conjunctivitis & $32 \%$ & $0 \%$ \\
\hline
\end{tabular}



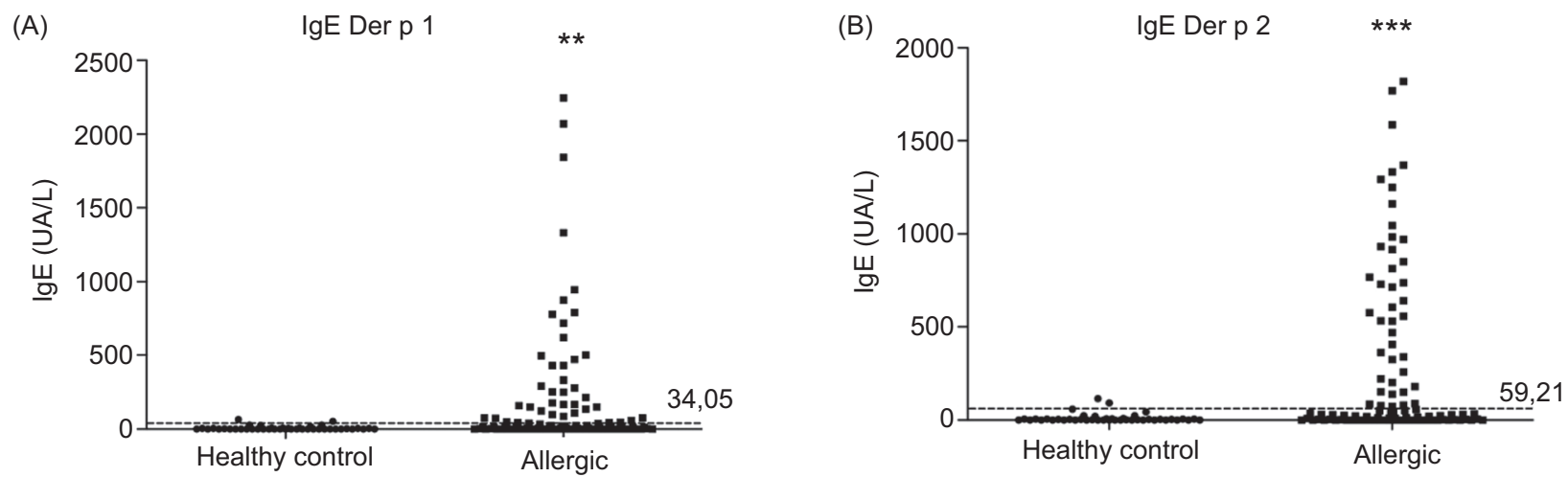

Figure 1 (A) Quantification of Der p 1-specific IgE; (B) Der $p 2$ in allergic patients $(n=98)$ and controls $(n=44)$. The results were expressed in arbitrary units per milliliter $(\mathrm{AU} / \mathrm{mL})$. The cut-off value (average $+2 \times \mathrm{SD})$ is indicated on the dotted line. The patients' antibody levels were compared with the healthy control by the Student's $t$-test ("* $\mathrm{P}<0.0001$, "“* $<<0.005$ ).
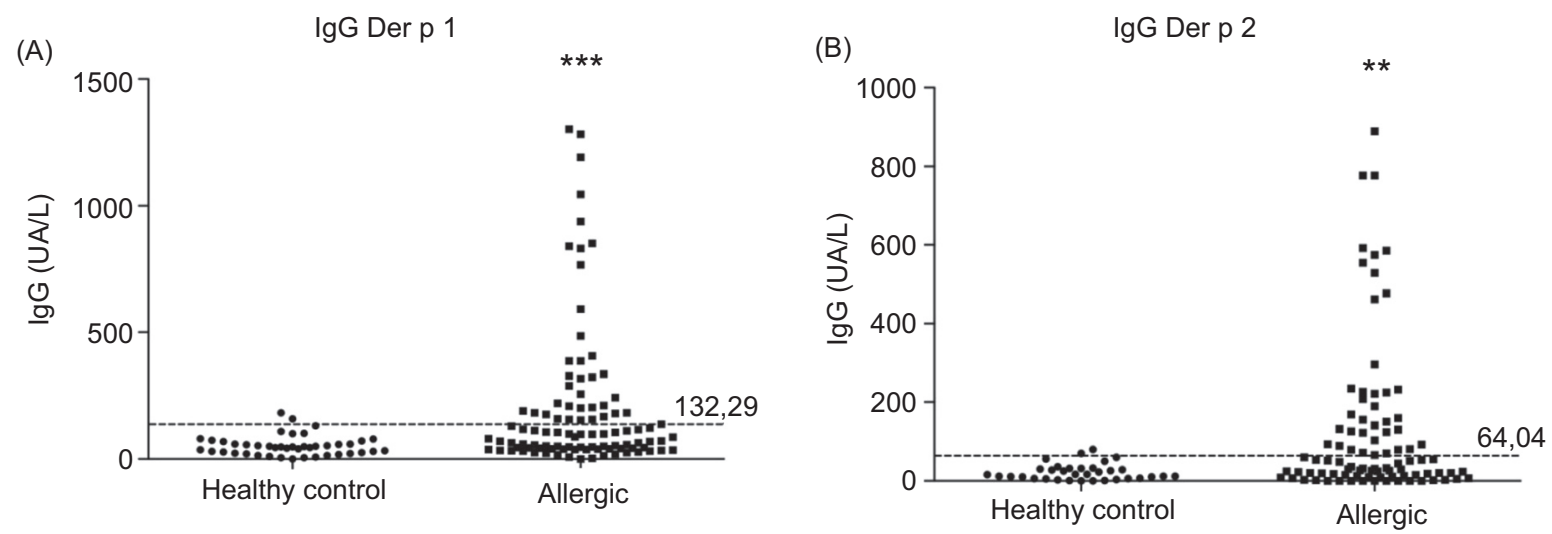

Figure 2 (A) Quantification of Der p 1-specific IgG; (B) Der p 2 in allergic patients $(n=98)$ and controls $(n=44)$. The results are expressed in arbitrary units per milliliter $(\mathrm{AU} / \mathrm{mL})$. The cut-off value (average $+2 \times \mathrm{SD})$ is indicated on the dotted line. The patient's antibody levels are compared with the healthy control by the Student's $t$-test $\left({ }^{* \star *} P<0.0001\right.$, " $\left.P<0.005\right)$.
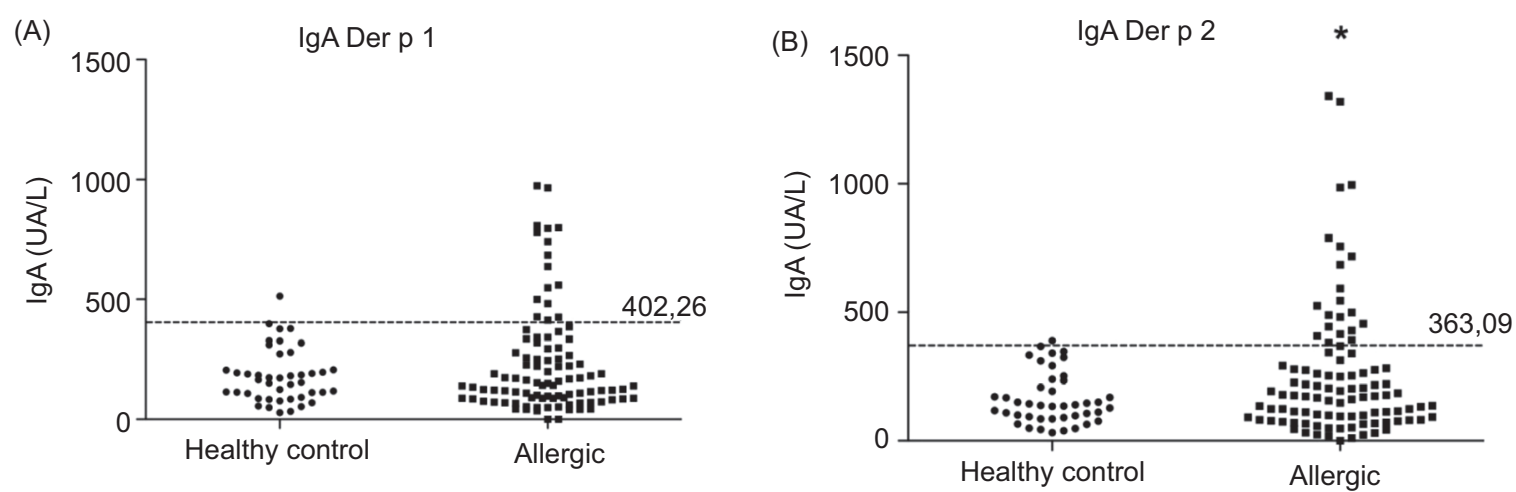

Figure 3 (A) Quantification of Der p 1-specific IgA; (B) Der p 2 in allergic patients $(n=98)$ and controls $(n=44)$. The results are expressed in arbitrary units per milliliter $(\mathrm{AU} / \mathrm{mL})$. The cut-off value (average $+2 \times \mathrm{SD}$ ) is indicated on the dotted line. The patient's antibody levels are compared with the healthy control by the Student's $t$-test ( $\mathrm{P}<0.05)$.

The difference observed between the levels of IgE as shown in Figures $1 \mathrm{~A}$ and $\mathrm{B}$ was already expected, since the presence of IgE specific to the mite was the criterion for the formation of groups. This quantification demonstrates that the members of the allergic group were also sensitive to the main allergens in the Der $\mathrm{p}$ mite, different from the control group. These results corroborate those found in literature, since other authors assessed the levels of IgE antibodies specific to Der p 1 and Der p 2 between atopic and non-atopic patients, and observed a similar result. ${ }^{22}$

Although present in allergic inflammation, we observed in our results that allergic patients showed high levels of IgG specific to Der $\mathrm{p} 1$ and Der p 2 concerning controls. It is worth mentioning that affinity maturation and antibody class change are the central processes in establishing effective $B$ cell memory. Affinity maturation is the 

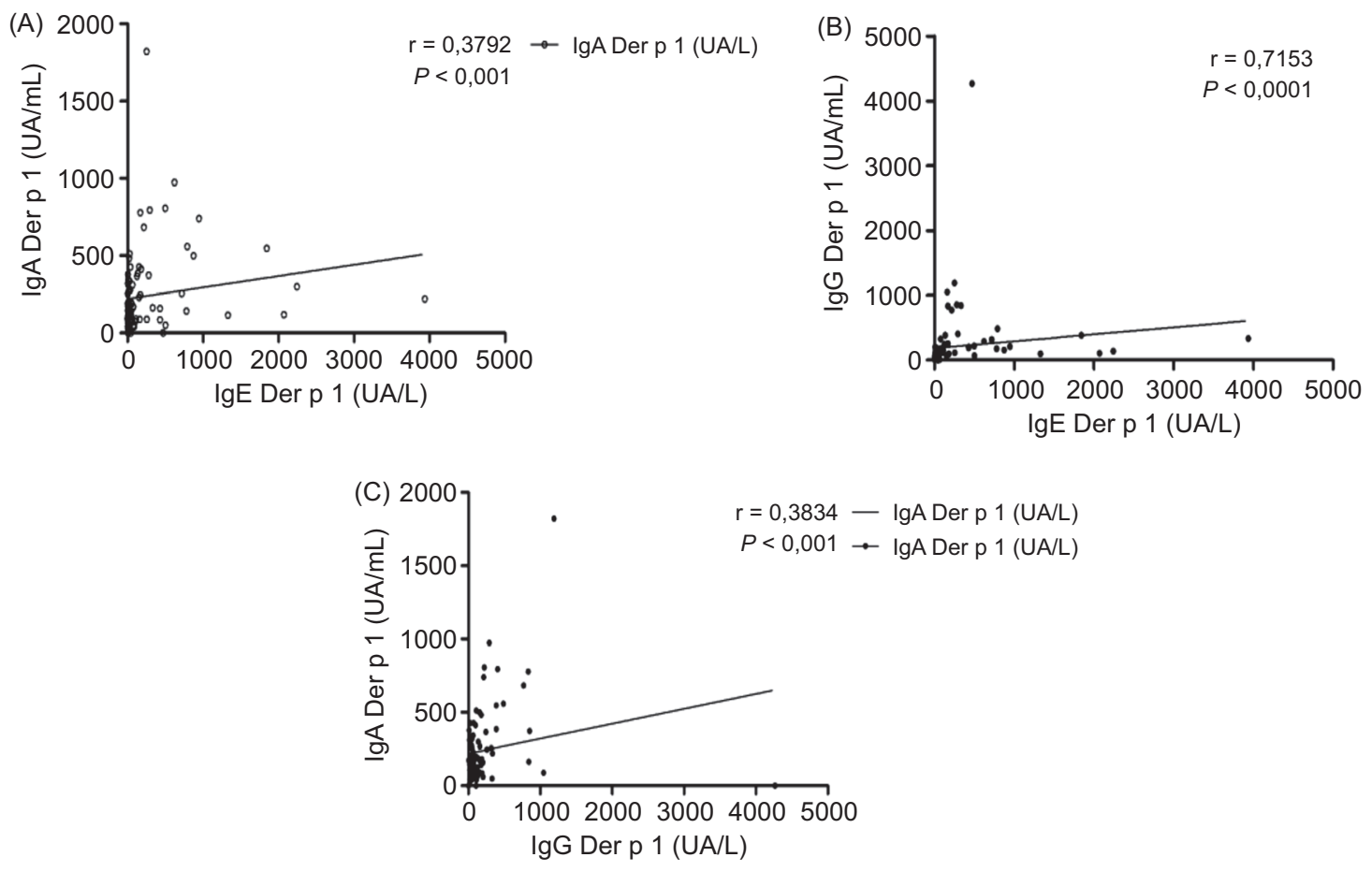

Figure 4 Correlation between the levels of specific antibodies to Der $\mathrm{p} 1$ for patients in the allergic group. (A) Correlation between IgA and IgE; (B) correlation between IgG and IgE; and (C) correlation between IgA and IgG. The analyses were performed using the Spearman correlation coefficient $(r), n=98$.

(A)

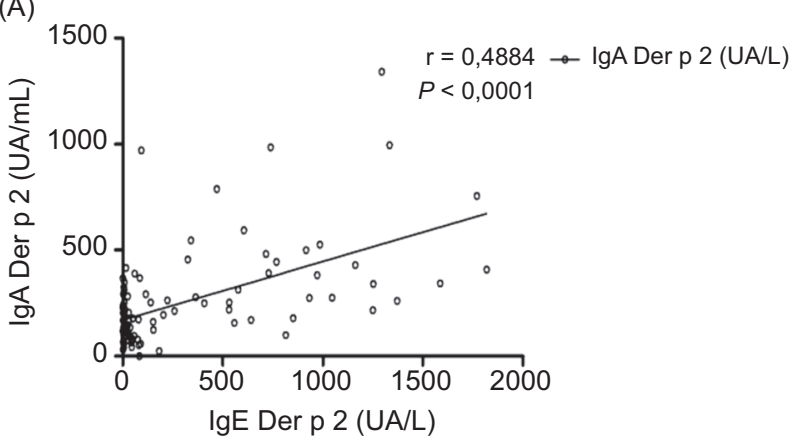

(B)

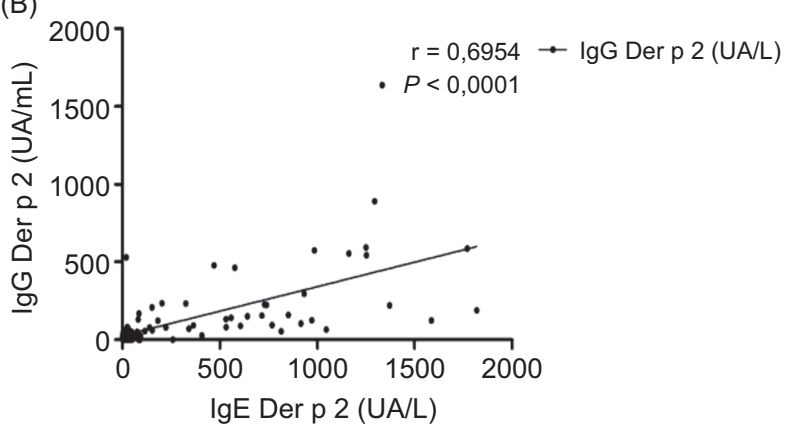

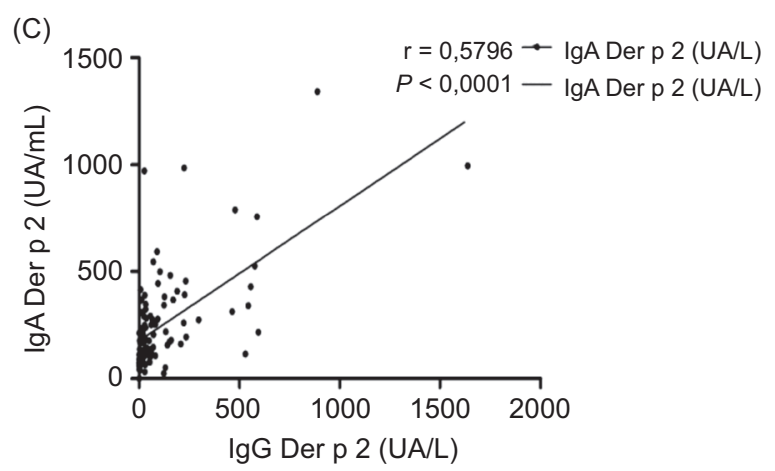

Figure 5 Correlation between the levels of specific antibodies to Der p 2 in patients of the allergic group. (A) Correlation between IgA and IgE; (B) correlation between IgG and IgE; and (C) correlation between IgA and IgG. The analyses were performed using the Spearman correlation coefficient $(r), \mathrm{n}=98$. 
mechanism in which $B$ cells improve the recognition of their cognate antigen by refining $B$ cell receptor (BCR) affinity. In humans, the production of IgE is generally associated with the production of $\operatorname{lgG} 1$ and $\operatorname{lgG} 4$. The main biological activity of IgE is derived from its ability to bind monomerically to high-affinity FceRI receptors in mast cells and basophils, inducing its degranulation by cross-linking caused by antigen binding. IgE also binds to FceRII (CD23) in $B$ cells, regulating the presentation of antigens and the production of $\operatorname{lgE} .^{23}$ This result is also consistent with the study conducted by Hales et al. ${ }^{24}$ who evaluated IgG levels in allergic patients. IgG is known mainly for its pathogen opsonization function; however, it can act to block mast cell degranulation, whereas IgE mediates the activation of cells sensitized by it. Studies have demonstrated by competition test with IgG and IgE antibodies that the IgG antibody has a similar binding to IgE, generating site competition. ${ }^{24}$ In comparison to our results, the allergic group also showed higher levels of Der $p$ 1- and Der $p$ 2-specific IgG, compared with the control group, indicating that there is some influence on the mechanism of allergic response, leading to IgG production in allergic patients. ${ }^{24,25}$ We can infer that increase in anti-mite IgG may show an attempt to control the exacerbated production of specific IgE with consequent immunological tolerance. Data from several studies with immunotherapy indicate that the increase in IgG, more specifically IgG4, is directly related to clinical improvement in allergic patients. ${ }^{26}$

In this study, we observed high levels of IgA in the allergic group compared with the control group. Regarding the increase in IgA, an indication that there is another mechanism of allergic response developed to tolerate or regulate inflammation can be perceived. However, as observed by other authors, some studies have evaluated specific IgA antibodies; ${ }^{27,28}$ however, the real role of specific IgA in attenuating allergic response has not yet been elucidated.

The study of the relationship between various antibodies determined here show that despite the difference found between specific IgE and IgG levels for both Der p 1 and Der $p 2$, there was a strong correlation between the levels of IgE and those of IgG. A study carried out by Schwarz and collaborators ${ }^{29}$ observed that the exposure route could interfere in the relationship of specific IgE and IgG antibodies to certain allergens. The frequency and intensity of the IgG-mediated response induced by natural exposure to allergenic molecules, according to Schwarz et al., is highly dependent on the route of exposure of allergens, being very frequent for allergens of animal and plant origin, and moderately frequent for mites. ${ }^{29}$ Regarding Der $\mathrm{p}$ 1-specific IgE and IgA, there was a weak correlation to Der $p$ 2-specific antibodies.

The correlation between Der $\mathrm{p}$ 2-specific IgA and IgG was moderate. Although there was a correlation, its strength was greater between IgE and IgG ( $r=0.7153$ for Der p 1 and 0.6954 for Der p 2) than between IgE and IgA $(r=0.3792$ for Der $p 1$ and 0.4888 for Der $p 2)$. These correlations, along with the results of the antibodies demonstrated previously, lead us to the Th1 versus Th2 paradigm.

We conclude that allergic patients have higher levels of IgG, IgA, and IgE against Der $\mathrm{p} 1$ and Der $\mathrm{p} 2$ compared with healthy controls. Since the pathophysiology of allergic diseases is complex and influenced by several factors, further studies are required to understand and clarify them.

\section{Author contributions}

All authors contributed to this research. Dircéu Solé and Carolina Sanchez Aranda contributed to the acquisition of samples and reading and reviewing the article, and Antonio Condino Neto and Leandro Hideki Ynoue contributed to the analysis of results and interpretation.

\section{Funding}

This project was funded by FAPESP, project number 2015/10532-5.

\section{References}

1. Tan H-TT, Sugita K, Akdis CA. Novel biologicals fot the treatment of allergic diseases and asthma. Curr Allergy Asthma Rep. 2016;16(70):1-14. https://doi.org/10.1007/s11882-016-0650-5

2. Hawrylowicz CM, Garra AO. Potencial role of interleukin-10 Secreting regulatory $T$ cells in allergy and asthma. Nature Rev. 2005;5:271-83.https://doi.org/10.1038/nri1589

3. Rutkowski K, Sowa P, Talipska JR, Sulkowski S, Rutkowski R. Allergic diseases: The price of civilisational progress. Derm Alergol. 2014;2:77-83.https://doi.org/10.5114/pdia.2014.40936

4. London Jr R, Tharakan A, Ramanathan Jr M. The role of innate immunity and aeroallergens in chronic rhinosinusites. Adv Otorhinolaryngol Basel (Karger). 2016;79:66-77.https://doi. org/10.1159/000445132

5. Yazdanbakhsh M, Kremsner PG, Ree van R. Allergy, parasites and the hygiene hypothesis. Science. 2002;296:490-4. https:// doi.org/10.1126/science.296.5567.490

6. Aranda CS, Cocco RR, Pierotti FF, Mallozi MC, Franco JM, Porto A, et al. Increased sensitization to several allergens over a 12-year period in Brazilian children. Pediatr Allergy Immunol. 2018;29(3):321-4. https://doi.org/10.1111/pai.12860

7. Platts-Mills TAE, de Weck AL. Dust mite allergens and asthma-A worldwide problem. J Allergy Clin Immunol. 1989;83:41627. https://doi.org/10.1016/0091-6749(89)90128-0

8. Criado RFJ, Wandalsen NF. Fatores ambientais em alergia. Alergia e Imunologia na Infância e na Adolescência. Atheneu. São Paulo. 2001:13-22.

9. Serravalle K, Medeiros M Jr. Ácaros da poeira domiciliar na cidade de Salvador-BA. Rev Bras Alerg Imunopatol. 1999;22:19-24.

10. Platts-Mills TAE, Chapman MD. Dust mites: Immunology, allergic disease, and environmental control. J Allergy Clin Immunol. 1987;80:755-77. https://doi.org/10.1016/S0091-6749(87)80261-0

11. Tsaia JJ, Shenb HD, Chuac KY. Purification of group 2 dermatophagoides pteronyssinus allergen prevalence of its specific IgE in asthmatics. Int Arch Allergy Immunol. 2000;121:205-210. https://doi.org/10.1159/000024318

12. Marie-Eve D, Herman J, Campizi V, Galleni M, Jacquet A, Chevigné A. Orchestration of an uncommon maturation cascade of the house dust mite protease allergen quartet. Front Immunol Immunotherap Vaccines. 2014;5(138):1-6. https:// doi.org/10.3389/fimmu.2014.00138

13. Valk van der JPM, Jong de NW, Wijk van RG. Review on immunotherapy in airway allergen-sensitised patients. Neth J Med. 2015;73(6):263-96. 
14. Till SJ, Francis JN, Nouri-Aria K, Path FRC, Durham SR. Molecular mechanisms in allergy and clinical immunology. J Allergy Clin Immunol. 2004;113(6):1025-34.https://doi. org/10.1016/j.jaci.2004.03.024

15. Shamji MH, Durham SR. Machanisms of allergen immunotherapy for inhaled allergens and predictive biomarkers. J Allergy Clin Immunol. 2017;140(6):1485-98. https://doi.org/10.1016/j. jaci.2017.10.010

16. Uphan JW. The role of dendritic cells in immune regulation and allergic airway inflammation. Respirology. 2003;8:140-48. https://doi.org/10.1046/j.1440-1843.2003.00465.x

17. Chauveau A, Dalphin ML, Mauny F, Kaulek V, SchmausserHechfellner E, Renz $\mathrm{H}$, et al. Skin prick tests and specific lgE in 10-year-old children: Agreement and association with allergic diseases. Allergy. 2017;72(9):1365-1373. https://doi. org/10.1111/all.13148

18. Haahtela T, Burbach GJ, Bachert C, Bindslev-Jensen C, Bonini $\mathrm{S}$, Bousquet $\mathrm{J}$, et al. Clinical relevance is associated with allergen-specific wheal size in skin prick testing. Clin Exp Allergy. 2014;44:407-416. https://doi.org/10.1111/cea.12240

19. Boechat JL, França AT. Atopic march. Revista Brasileira de Alergia e Imunopatologia. 2008;31(4):139-45.

20. Roche N, Chinet TC, Huchon GJ. Allergic and nonallergic interactions between house dust mite allergens and airway mucosa. Eur Resp J. 1997;10:719-26.

21. Rönmark EP, Ekerljung L, Mincheva R, Sjölander S, Hagstads Wennergren G, Rönmark E, et al. Different risk factor patterns for adult asthma, rhinitis and eczema: Results from West Sweden Asthma Study. Clin Translat Allergy. 2016;6(28):1-10. https://doi.org/10.1186/s13601-016-0112-0

22. Minami T, Fukutomi Y, Lidholm J, Yasueda H, Saito A, Sekiya K, et al. IgE abs to Der p 1 and Der $p 2$ as diagnostic markers of house dust mite allergy as defined by a bronchoprovocation test. Allergil Int. 2015;64:90-95. https://doi.org/10.1016/j. alit.2014.08.004

23. Saunders SP, Ma EGM, Aranda CJ, Curotto de Lafaille MA. Non-classical B cell memory of allergic IgE responses. Front Immunol. 2019;10:715. https://doi.org/10.3389/fimmu.2019. 00715

24. Hales BJ, Martin AC, Pearce LJ, Laing IA, Hayden CM, Goldblatt J, et al. IgE and IgG anti-house dust mite specificities in allergic disease. J Allergy Clin Immunol. 2006;118:361-7. https://doi.org/10.1016/j.jaci.2006.04.001

25. Smart JM, Kemp AS. Increased Th1 and Th2 allergen-induced cytokine response in children with atopic disease. Clin Exp Allergy. 2002;32:796-802. https://doi. org/10.1046/j.1365-2222.2002.01391.x

26. Akdis CA, Akdis M. Mechanisms of immune tolerance to allergens: Role of IL-10 and T regs. J Clin Invest. 2014;124(11):467880. https://doi.org/10.1172/JCl78891

27. Kim JH, Yoon MG, Seo DH, Kim BS, Ban GY, Ye YM, et al. Detections of allergen specific antibodies from nasal secretion of allergic rhinitis patients. 2016;8(4):329-37. https://doi. org/10.4168/aair.2016.8.4.329

28. Suzuki K, Fagarsan S. Diverse regulatory pathways for IgA syntesis in the gut. Mucosal Immunol Nature. 2009;6(2):468-471. https://doi.org/10.1038/mi.2009.107

29. Schwarz A, Panetta V, Capella A, Hofmaier S, Hatzler L, Rohrbach A, et al. IgG and IgG4 to 91 allergenic molecules in early childhood by route of exposure and current and future IgE sensitization: Results from the Multicentre Allergy Study birth cohort. J Allergy Clin Immunol. 2016;138(5):1426-33. https://doi.org/10.1016/j.jaci.2016.01.057 